FACTA UNIVERSITATIS

Series: Mechanical Engineering Vol. 18, N² 2, 2020, pp. 165 - 188

https://doi.org/10.22190/FUME200615026F

Original scientific paper

\title{
EFFECT OF FIBER ORIENTATION PATH ON THE BUCKLING, FREE VIBRATION AND STATIC ANALYSES OF VARIABLE ANGLE TOW PANELS
}

\section{Nasim Fallahi, Andrea Viglietti, Erasmo Carrera, Alfonso Pagani, Enrico Zappino}

$\mathrm{MUL}^{2}$ team, Department of Mechanical and Aerospace Engineering, Politecnico di Torino, Italy

\begin{abstract}
In this work, the effect of the fiber orientation on the mechanical response of variable angle tow (VAT) panels is investigated. A computationally efficient high-order one-dimensional model, derived under the framework of the Carrera unified formulation $(C U F)$, is used. In detail, a layerwise approach is adopted to predict the complex phenomena that may appear in VAT panels. Static, free-vibration and buckling analyses are performed, considering several material properties, geometries, and boundary conditions, and the results are assessed with those obtained using existing approaches. Considering the findings of the comparative analysis, several best design practices are suggested to improve the mechanical performances of VAT panels.
\end{abstract}

Key Words: Variable Angle Tow, Carrera Unified Formulation, Buckling, Free Vibration, Static Analysis

\section{INTRODUCTION}

Advanced tow placement techniques allow fiber to be placed along a curvilinear pattern within each layer. This has led to the emergence of a new class of composite materials named variable angle tow (VAT) laminates. Compared to the classical composites, the VAT laminates provide a more extensive design space and allow engineers to further optimize the final structure in terms of the minimum weight or maximum strength/stiffness $[1,2,3]$. In the VAT laminates, the fiber orientation angles vary spatially, owing to which the stiffness

Received June 15, 2020 / Accepted July 18, 2020

Corresponding author: Nasim Fallahi

Department of Mechanical and Aerospace Engineering, Politecnico di Torino, Corso Duca degli Abruzzi, 10129, Turin, Italy.

E-mail: nasim.fallahi@polito.it 
properties exhibit local variations. Such a stiffness variation can be discrete or continuous with curvilinear fiber paths [4, 5, 6, 7]. It has been reported that VAT laminates can improve the structural performance such as the strength and buckling characteristics, and freevibration response of composite structures compared to the corresponding values for classical composites $[8,9]$.

Hyer and Lee [10] improved the buckling load in a plate with a circular hole by using variable stiffness composites. Several investigations based on numerical models [3, 11, 12] and experimental tests [13] demonstrated the advantages of VAT panels in preventing buckling. Moreover, the analysis of VAT structures has not been limited to simple problems but has dealt with various cases such as composite cylinders $[14,15]$, thin plates and thinwalled structures [16, 17, 18], for improving first ply failure modes [19], and simply supported rectangular plates under non-uniform uniaxial compression [20]. In addition, the introduction of VAT composites can improve the buckling and postbuckling load-carrying capacity under in-plane positive and negative shear loading [21]. Furthermore, Hao et al. [22] investigated the buckling response of variable-stiffness composite panels by employing the Mindlin plate theory in conjunction with the isogeometric analysis and demonstrated that the classical finite element models cannot accurately describe the stiffness variation in VAT structures. VAT laminates can also be used to modify the dynamic response of composite structures by tailoring the overall structural stiffness. This aspect can be attributed to the effect of the parabolic fiber orientation angles, cutout size, thickness, and boundary conditions on the characteristics of the VAT composites [23]. Stodieck et al. [24] used a simple mathematical rigid plate model to examine the effect of the VAT lay-ups, particularly, the fiber angle variation, on the aeroelastic performance of a wing. Furthermore, Zhao and Kapania [25] used the finite element method to investigate the prestressed free vibration of a simply supported VAT laminated plate under uniform end shortening. Honda et al. [26] formulated an optimum design methodology to propose novel reinforced composite plates with locally anisotropic structures. In addition, Akhavan et al. [27] employed a new p-version finite element method to perform the natural frequency and mode shape analyses of rectangular plates made of variable stiffness composite laminates. Labans and Bisagni [28] conducted both numerical and experimental investigations pertaining to the buckling and free-vibration response of constant and variable-stiffness cylindrical shells. Moreover, Samukham et al. [29] used the finite element method to study the dynamic instability of VAT composite plates subjected to in-plane loading. The authors employed the first-order shear deformation theory as the displacement field model to derive the governing equations and examined the effect of different parameters including the fiber angle orientation, load parameters, boundary conditions, orthotropy ratio and aspect ratio on the system response. The generalized differential integral quadrature method can be combined with the Rayleigh-Ritz method to solve the governing differential equation corresponding to the parametric instability problem of VAT panels [30]. In a curved panel with VAT laminates, the boundary conditions and fiber angles considerably influence the buckling and dynamic instability behavior [31]. Furthermore, it has been reported that fiber placement at an angle of $0^{\circ}$ and thickness build-up at transversely supported regions of composite panels can help realize a high axial compressive stiffness [32].

Viglietti et al. [33]. used refined one-dimensional models based on the Carrera unified formulation (CUF) to investigate VAT laminates on the dynamic response of complex wing structures. Vescovini and Dozio [34] proposed an accurate approximation technique 
to perform the vibration and buckling analyses of variable stiffness plates by using the CUF approach in combination with the Ritz method. Their results pertained to thick variable stiffness laminates such as monolithic and sandwich structures under any combination of boundary conditions. Furthermore, a three-dimensional stress field was accurately identified using 1D CUF models with a higher computational efficiency compared to that when using 3D finite element models [35]. The advantages of the layerwise method in the analysis of VAT and sandwich beam structure were also demonstrated by Patni et al. [36]. Specifically, the authors considered the three-dimensional (3D) stress distribution derived using hierarchical serendipity Lagrange finite elements and reported on the enhanced structural performance of VAT structures compared to that of traditional straight-fiber composites [37]. Several studies have reported on the application of the CUF in various cases involving plates, shells, beams, thermoelastics, piezo-electric problems, and aeroelastic applications [38, 39, 40, 41, 42]. In particular, in the 1D CUF beam theory, a polynomial expansion is used to describe the displacement field over the cross-section, allowing the order of the expansion to be considered as a free parameter of the formulation. Refined 1D beam models can be modeled based on the equivalent single layer (ESL) or layerwise (LW) theories. However, the ESL cannot describe the continuity of transverse stresses and zigzag behavior of the displacement along with the thickness of composite layers $[43,44,45]$. In addition, LW theories are defined based on the dependency between the number of unknown parameters and layers [46, 47, 48, 49]. Thus, to expand the displacement fields over the cross-section, a Taylor expansion with a generic N-order [50, 51] or Lagrange polynomial expansion can be used.

This discussion indicates that although several reports exist regarding the static and dynamic analyses of VAT composite panels performed under the framework of various displacement models as well as different approximation approaches, the effect of the fiber orientation angle on the static, buckling and free-vibration response of VAT composite plates under various boundary conditions has not been extensively investigated. Therefore, in this work, a high-fidelity one-dimensional beam model is used to study the natural frequencies, critical buckling load, and static response of composite plates made of VAT laminates. The results are validated by performing a comparative analysis with several existing approaches. Furthermore, a parametric study is performed to examine the influence of various parameters such as the fiber orientation angle, material properties, boundary conditions, and geometry dimensions on the performance of the laminates. In addition, while many works consider the static, free-vibration and bulking analysis separately, in this work all the problems are examined together in order to show that the best panel design is not the one that gives better performances in one of the single analyses, but a better design comes from a trade-off to obtain acceptable performance in all the operational scenarios.

\section{VAT LAMINATES}

To represent the variable stiffness properties, the fiber orientation angle can be varied continuously in each ply along either the $\mathrm{x}$ or $\mathrm{y}$ coordinates or both the coordinates. Such design flexibility enables the VAT composite to enhance the structural performance. The variation in the VAT fiber angles can be mathematically formulated using only a few parameters [52]. Thus, in the present work, a VAT plate with a linear variation in the fiber 
angle is defined using the following notation to describe the fiber pattern in the VAT laminates $[8,53]$.

$$
\theta(y)=2\left(T_{1}-T_{0}\right) \frac{|y|}{a}+T_{0}
$$

The desired stiffness and strength can be achieved by introducing two different angles, $T_{0}$ and $T_{1}$ which denote the lamination angle at the center and edge of the composite laminates, respectively. $\theta(y)$ is related to the fiber variation along the y-axis, $a$ is the width of the VAT panel, and $b$ is the length of the laminate. Fig. 1 illustrates the coordinate system for the VAT lamina with a curvilinear fiber design.

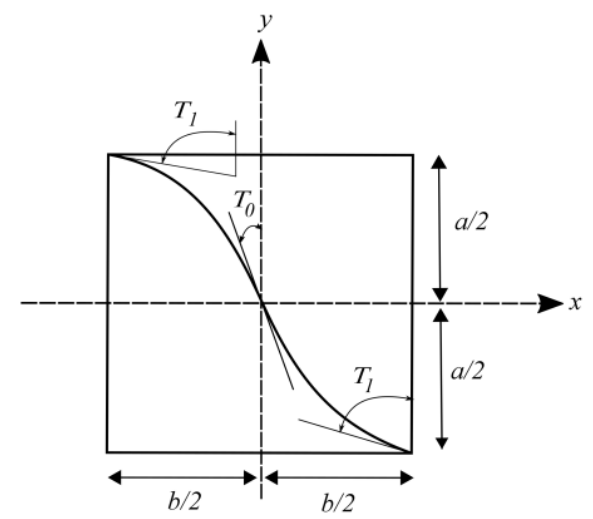

Fig. 1 VAT composite model

\section{NUMERICAL MODEL}

\subsection{Preliminaries}

The notations and quantities employed in this work are introduced based on continuum mechanics. The VAT structures are modeled by using a refined onedimensional model based on the CUF. With no loss of generality, the length of the beam structures is defined along the $y$ axis, and the cross-section is defined on the $x z$-plane. The displacement vector is denoted as $\boldsymbol{u}$. Superscript $T$ denotes transposition; $\boldsymbol{\sigma}$ and $\boldsymbol{\epsilon}$ denote the stress and strain vectors, respectively.

$$
\begin{gathered}
\boldsymbol{u}(x, y, z)=\left\{u_{x} u_{y} u_{z}\right\}^{T} \\
\boldsymbol{\sigma}(x, y, z)=\left\{\sigma_{x x}, \sigma_{y y}, \sigma_{z z}, \sigma_{x y}, \sigma_{x z}, \sigma_{y z}\right\}^{T} \\
\boldsymbol{\epsilon}(x, y, z)=\left\{\epsilon_{x x}, \epsilon_{y y}, \epsilon_{z z}, \epsilon_{x y}, \epsilon_{x z}, \epsilon_{y z}\right\}^{T}
\end{gathered}
$$

where $\epsilon$ is strain and is defined using a linear differential operator $\boldsymbol{b}(6 \times 3$ matrix [54]):

$$
\epsilon=b u
$$


Furthermore, based on Hooke's law, the stress vector can be expressed as:

$$
\boldsymbol{\sigma}=\boldsymbol{C} \epsilon
$$

where $\boldsymbol{C}$ is the matrix of the elastic coefficients of the material, which can be considered as a variable of the space coordinates in the case of VAT panels, as described in detail in the subsequent sections.

\subsection{Variable kinematics of one-dimensional models}

The displacement field for the beam structure in the CUF can be defined as:

$$
\boldsymbol{u}(x, y, z)=F_{\tau}(x, z) \boldsymbol{u}_{\tau}(y), \quad \tau=1,2, \ldots, M
$$

where $F_{\tau}$ is an arbitrary cross-section expansion over the $x, z$-plane, $\boldsymbol{u}_{\tau}(\mathrm{y})$ is a generalized displacement vector, and $M$ is the number of expansion terms. The kinematics of the model can be modified according to function $F_{\tau}$. In this work, 9 and 16 node Lagrange elements are used as $F_{\tau}$ expansion polynomials, and they are denoted as L9 and L16, respectively. These expansions are used to formulate cubic and quadratic higher-order kinematics, respectively. The L9 polynomial expansion can be summarized as follows (for more details, please refer to $[54,55])$ :

$$
\begin{aligned}
& u_{x}=F_{1} u_{x 1}+F_{2} u_{x 2}+\ldots+F_{9} u_{x 9} \\
& u_{y}=F_{1} u_{y 1}+F_{2} u_{y 2}+\ldots+F_{9} u_{y 9} \\
& u_{z}=F_{1} u_{z 1}+F_{2} u_{z 2}+\ldots+F_{9} u_{z 9}
\end{aligned}
$$

where $F_{1}, F_{2}, \ldots ., F_{9}$ denote the Lagrange L9 set over the cross-section, and $u_{x 1}, u_{y 1}, u_{z 1}$, ...., $u_{z} 9$ denote 27 unknown displacement variables that represent the pure displacement components at each node of the L9 element. In the L9 set, the interpolation functions are as follows:

$$
\begin{aligned}
& F_{\tau}=\frac{1}{4}\left(\alpha^{2}+\alpha \alpha_{\tau}\right)\left(\beta^{2}+\beta \beta_{\tau}\right) \quad \tau=1,3,5,7 \\
& F_{\tau}=\frac{1}{2} \beta_{\tau}^{2}\left(\beta^{2}+\beta \beta_{\tau}\right)\left(1-\alpha^{2}\right)+\frac{1}{2} \alpha_{\tau}^{2}\left(\alpha^{2}+\alpha \alpha_{\tau}\right)\left(1-\beta^{2}\right) \quad \tau=2,4,6,8 \\
& F_{\tau}=\left(1-\alpha^{2}\right)\left(1-\beta^{2}\right) \quad \tau=9
\end{aligned}
$$

where $\alpha$ and $\beta$ denote the normalized coordinates and vary over the interval $[-1,+1]$; for more details, please refer to [56].

The Lagrange expansions allow the laminate to be investigated using an LW approach in which an individual kinematics is defined for each layer. Therefore, the cross-sections are defined separately in the laminate layers and in each single ply. The use of the LW improves the accuracy of determination of the mechanical behavior compared to that obtained using the classical model based on the ESL [57]. In this manner, the actual description of the laminates can be obtained, as shown in Fig. 2. 

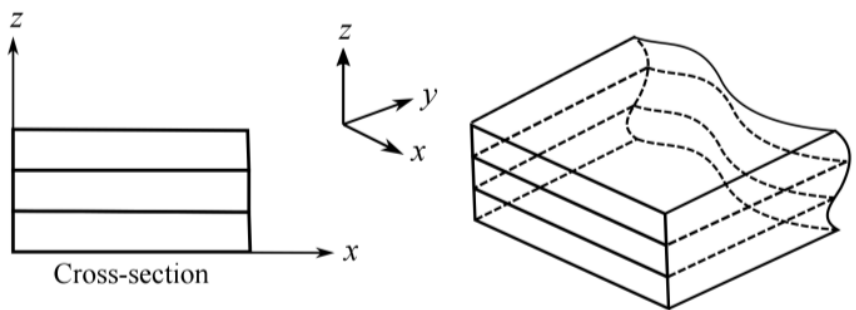

Fig. 2 Each layer is modeled independently in the case of layerwise approach

where the finite element method is adopted along the y-axis for the discretization of the structure with the generalized displacement vector, which is approximated as:

$$
\boldsymbol{u}(x, y, z)=F_{\tau}(x, z) N_{i}(y) \boldsymbol{q}_{\tau i} \quad i=1,2 \ldots, K
$$

Here, index $i$ denotes the number of nodes of the beam element, $N_{i}(y)$ is the shape function, $\boldsymbol{q}_{\tau i}$ denotes the nodal unknowns, and $K$ is the number of nodes on the element. Based on the principal virtual displacement, the virtual internal work can be expressed as:

$$
\delta L_{i n t}=\int_{V} \delta \epsilon^{T} \sigma d V
$$

where $V$ is the volume of the element, and $\delta \epsilon$ is the virtual variation of the strain, which is presented as:

$$
\delta \boldsymbol{\epsilon}=\boldsymbol{b} \delta \boldsymbol{u}=\boldsymbol{b}\left(F_{s}(x, z) N_{j}(y)\right) \delta \boldsymbol{q}_{s j}
$$

where $F_{s}$ stands as an arbitrary cross-section expansion, $N_{j}$, is shape function, and $\delta \boldsymbol{q}_{s j}$ is the virtual variation nodal unknown. By combining Eqs. (6), (7), (11), and (12), the geometrical relations can be obtained in the linear form. Therefore, the virtual variation of the internal work can be defined as:

$$
\begin{gathered}
\delta L_{\text {int }}=\delta \boldsymbol{q}_{s j}^{\boldsymbol{T}} \int_{V} \boldsymbol{b}^{\boldsymbol{T}} N_{j}(y) F_{s}(x, z) \boldsymbol{C} \boldsymbol{b} F_{\tau}(x, z) N_{i}(y) d V \boldsymbol{q}_{\boldsymbol{\tau} i} \\
\quad \text { Fundamental Nucleus } \\
=\delta \boldsymbol{q}_{s j}^{T} \boldsymbol{k}^{\tau s i j} \boldsymbol{q}_{\tau i}
\end{gathered}
$$

According to CUF, $\boldsymbol{k}^{\tau s i j}$ is a $(3 \times 3)$ matrix and is termed as the stiffness fundamental nucleus (FN). In terms of the path function for the VAT composites, each layer involves pointby-point continuous angle variations with different values. In the case of VAT, the components of the FN are subjected to volume integrals. Thus, only two terms of the FN are considered in the following analysis, and the other terms can be obtained by permutations [54]:

$$
\begin{aligned}
& k_{x x}^{\tau s i j}=\int_{V} C_{22} F_{\tau, x} F_{s, x} N_{i} N_{j} d V+\int_{V} C_{66} F_{\tau, z} F_{s, z} N_{i} N_{j} d V+\int_{V} C_{44} F_{\tau} F_{s} N_{i, y} N_{j, y} d V \\
& k_{x y}^{\tau s i j}=\int_{V} C_{23} F_{\tau} F_{s, x} N_{i, y} N_{j} d V+\int_{V} C_{44} F_{\tau, x} F_{s} N_{i} N_{j, y} d V
\end{aligned}
$$

In this case, stiffness coefficients $\boldsymbol{C}$ vary within the computational domain; therefore, these coefficients must remain inside the integral of the FN. 


\subsection{Numerical implementation of the VAT concept}

In general, when using finite elements, integrals can be obtained by using the wellknown Gauss-Legendre formula. The integral form of the function is evaluated in the $(\eta, \xi)$ domain by considering a natural system (for more details, please refer to Carrera et al. [54]). In the VAT structure, each fiber path can be defined as an arbitrary function, and the fibers follow a curvilinear pattern. Hence, each position corresponds to a different stiffness value. Furthermore, in the VAT composite, the lamination angle should be accurately defined in the entire domain of the plate, in which $\boldsymbol{C}$ is no longer constant. In this manner, the integral can be introduced in the unique form of the volume, as presented in Eq. (14). In this work, the Gauss integration technique is used, and the material coefficients in the VAT composite can be evaluated in a specific Gauss point. Therefore, in the CUF framework, the real values of the lamination angle at each Gauss point are considered. Furthermore, the use of the 1D CUF beam model ensures a smoother approximation of the component stiffness compared with that obtained using the finite element method; for more details, please refer to [58]. Fig. 3 illustrates a simplified example of the VAT concerning the Gauss points for four nodes; in contrast, nine Gaussian points were used in the present study.

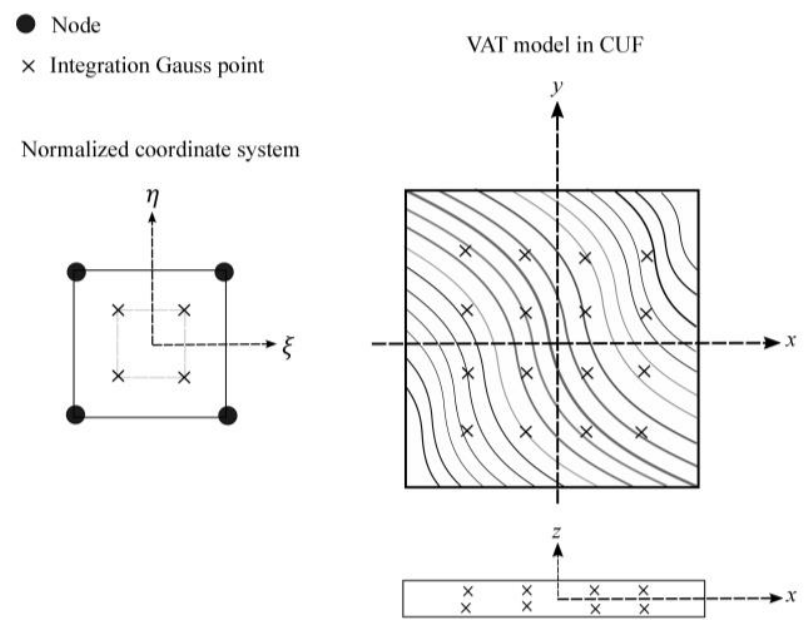

Fig. 3 VAT definition by Gaussian points

The CUF material properties can be evaluated in the VAT case by defining the correct Gauss integration point-to-point in the lamination by calculating the FN [54].

\subsection{Linearized buckling equations}

This section focuses on the linearized buckling problems. The tangent stiffness matrix can be obtained by linearizing the virtual variation of internal strain energy $\delta\left(\delta L_{\text {int }}\right)$ :

$$
\delta\left(\delta L_{i n t}\right) \approx \delta \boldsymbol{q}_{\tau i}^{T} \boldsymbol{k}^{\tau s i j} \delta \boldsymbol{q}_{s j}+\int_{V} \delta(\delta \boldsymbol{\epsilon})^{T} \boldsymbol{\sigma}^{0} d V
$$

where $\delta\left(\delta L_{\text {int }}\right)$ is calculated considering the sum of the linear stiffness and virtual variation work associated with the initial stresses $\sigma^{0}$. Subsequently, by using the CUF formulation 
in Eq. (7) and FEM in Eqs. (10) and (16), the following formulation can be obtained based on the Green-Lagrange nonlinear strain and displacement relations (see Carrera et al. [55]):

$$
\delta\left(\delta L_{i n t}\right) \approx \delta \boldsymbol{q}_{\tau i}^{T} \boldsymbol{k}^{\tau s i j} \delta \boldsymbol{q}_{s j}+\delta \boldsymbol{q}_{\tau i}^{T} \boldsymbol{k}_{\sigma^{0}}^{\tau s i j} \delta \boldsymbol{q}_{s j}=\delta \boldsymbol{q}_{\tau i}^{T}\left(\boldsymbol{k}^{\tau s i j}+\boldsymbol{k}_{\sigma^{0}}^{\tau s i j}\right) \delta \boldsymbol{q}_{s j}
$$

where $\boldsymbol{k}^{\tau s i j}$ is the same as in Eq. (14), and a new $\boldsymbol{k}_{\sigma^{0}}^{\tau s i j}$ appears in the form of a diagonal matrix, which is investigated as the FN of the geometrical stiffness matrix and is expressed for the buckling case as follows:

$$
\begin{aligned}
& \boldsymbol{k}_{\sigma^{0}}^{\tau s i j}=\left(\int_{V} \sigma_{x x}^{\mathbf{0}} F_{\tau, x} F_{s, x} N_{i} N_{j} d V+\int_{V} \sigma_{y y}^{\mathbf{0}} F_{\tau} F_{s} N_{i, y} N_{j, x} d V+\int_{V} \sigma_{z z}^{\mathbf{0}} F_{\tau, z} F_{s, z} N_{i} N_{j} d V\right. \\
& +\int_{V} \sigma_{x y}^{\mathbf{0}} F_{\tau, x} F_{s} N_{i} N_{j, y} d V+\int_{V} \sigma_{x y}^{\mathbf{0}} F_{\tau} F_{s, x} N_{i, y} N_{j} d V+\int_{V} \sigma_{x z}^{\mathbf{0}} F_{\tau, x} F_{s, z} N_{i} N_{j} d V \\
& \left.+\int_{V} \sigma_{x z}^{\mathbf{0}} F_{\tau, z} F_{s, x} N_{i} N_{j} d V+\int_{V} \sigma_{y z}^{\mathbf{0}} F_{\tau, z} F_{s} N_{i} N_{j, y} d V+\int_{V} \sigma_{y z}^{\mathbf{0}} F_{\tau} F_{s, z} N_{i, y} N_{j} d V\right) \boldsymbol{I}
\end{aligned}
$$

In Eq. (17), the stress tensor is determined by the 9 components corresponding to a $3 \times 3$ identity matrix $\boldsymbol{I}$. Moreover, depending on shape function $\left(N_{i}\right)$ and function $F_{\tau}$ over the cross-section, any desired beam model can be accessible in the CUF framework. Finally, the global matrices are assembled in the classical FEM. The critical buckling loads are determined as initial stress states $\boldsymbol{\sigma}^{0}$, which render the tangent stiffness matrix singular; i.e., $\left|\boldsymbol{K}+\boldsymbol{K}_{\sigma}^{\mathbf{0}}\right|=0$ [55].

\subsection{Free Vibration Equations}

Under the CUF framework, the same approach as that based on Eqs. (10-13) can be employed for solving free vibration. Subsequently, the work done by the inertial forces provides the fundamental nucleus of the mass matrix, as defined in Carrera et al. [55]:

$$
\delta L_{\text {ine }}=\int_{V} \rho \ddot{\boldsymbol{u}} \delta \boldsymbol{u}^{T} d V
$$

where $\rho$ is the material density, and $\ddot{\boldsymbol{i}}$ denotes the acceleration vector. From this expression, the FN of the mass matrix can be found straightforwardly and be used to solve usual free vibration problems.

\section{RESUlts AND MODEL VALIDATION}

\subsection{Convergence analysis for a single-layer VAT panel}

A convergence analysis is performed considering a single-layer VAT plate comparing different kinematic models and meshes with a different refinement level. The results are validated using a classical FE model developed in Nastran. The properties of the lamina are as follows: $E_{1}=50 \mathrm{GPa}, E_{2}=E_{3}=10 \mathrm{GPa}, G_{12}=G_{13}=G_{23}=5 \mathrm{GPa}, v_{12}=0.25$, with a thickness of $0.02 \mathrm{~m}$ and dimensions $a=b=1 \mathrm{~m}$. A linear variation of the fiber orientation is considered and expressed using parameter $\left\langle\mathrm{T}_{0} \mid \mathrm{T}_{1}\right\rangle$, as shown in Eq. (1). The boundary conditions are shown in Fig. 4. 


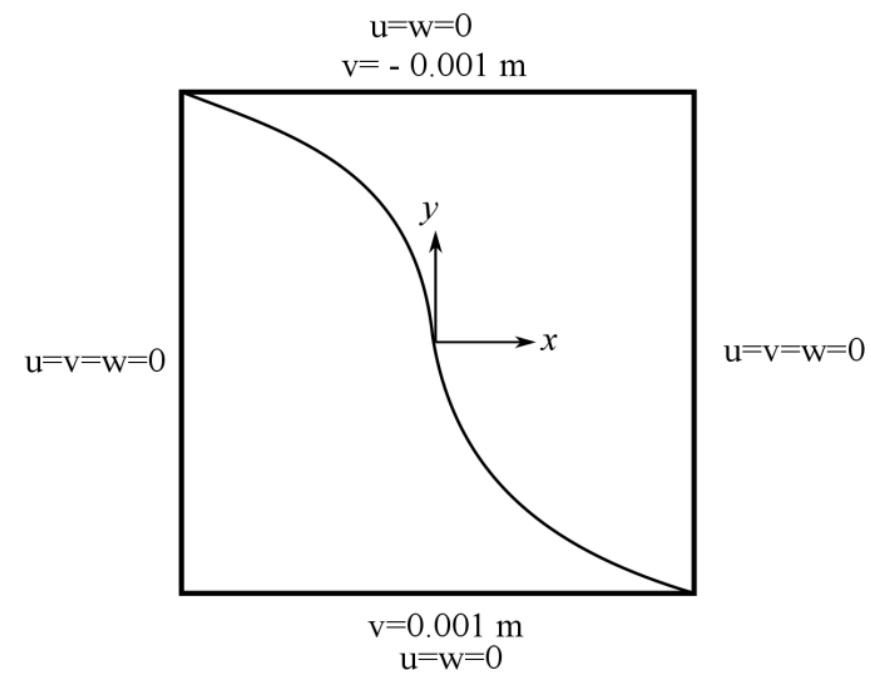

Fig. 4 Boundary conditions of the single-layer VAT plate, $\left\langle\mathrm{T}_{0} \mid \mathrm{T}_{1}\right\rangle=\left\langle 75^{\circ} \mid 15^{\circ}\right\rangle$

Cubic beam elements, B3, are used along the beam axis (y) with two different polynomial expansions, L9 and L16, to enable the beam kinematics approximation on the cross-section (xzcoordinates). At first, to evaluate the convergence of the models, refinement is performed along the $\mathrm{z}$-direction with $n_{z}{ }^{*}=(1,3,6,9)$ considering the L9 Lagrange polynomial expansions on the cross-section. In this case, the number of elements in the $\mathrm{x}$ and $\mathrm{y}$ directions (10B3) is considered constant (see Fig. 5). In the next step, refinement was performed simultaneously along the beam axis with $n_{y}{ }^{*}=(5,7,10,15,20,30) \mathrm{B} 3$ and along the plate width considering $n_{x}{ }^{*}=n_{y}{ }^{*}$. This refinement was performed considering both the L9 and L16 expansions on the cross-section, as shown in Figs. 6 and 7, respectively.

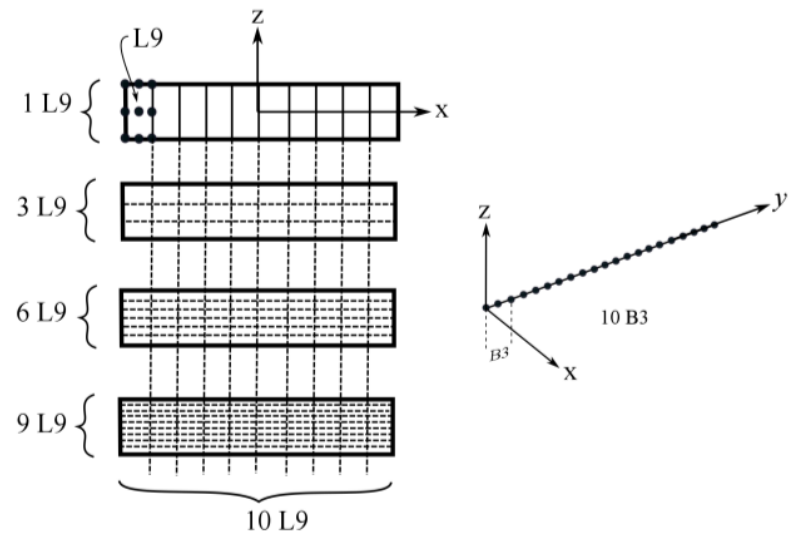

Fig. 5 Refined elements over the cross-section 


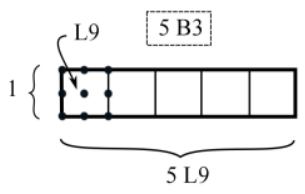

$15 \mathrm{~B} 3$

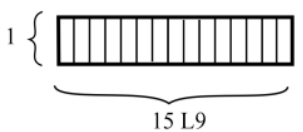

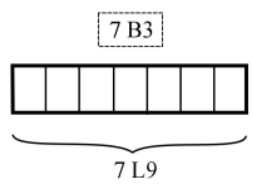

$20 \mathrm{~B} 3$

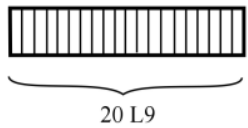

$10 \mathrm{~B} 3$

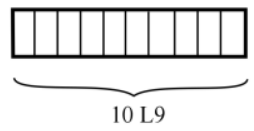

$30 \mathrm{~B} 3$

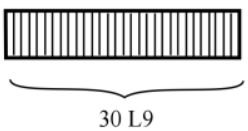

Fig. 6 Refined elements through the beam with L9 expansion over the cross-section

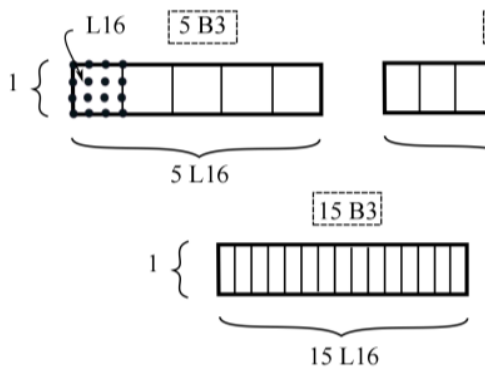

$7 \mathrm{~B} 3$
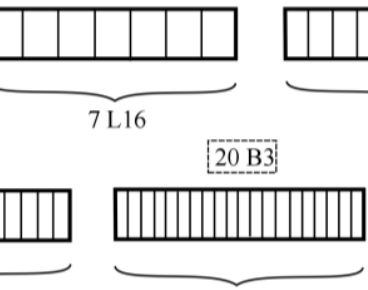

$20 \mathrm{~L} 16$

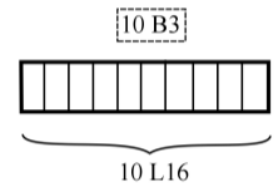

Fig. 7 Refined elements through the beam with L16 expansion over the cross-section

Table 1 summarizes the results obtained for the first and second critical buckling loads for each of the models considered. The results indicate the convergence of the proposed CUF approach with a significantly lower number of DOF as compared to those used in the Nastran model (see Figs. 8 and 9). Furthermore, the results indicate that the CUF model with L9 polynomial expansions and 10B3 beam elements can converge satisfactorily compared to the Nastran model. Therefore, this mesh can be employed for further modeling.

\subsection{Pre-buckling and buckling analyses of a sixteen-layer VAT plate}

A 16-ply balanced symmetric square plate, proposed in [22], is considered in this section. The square plate has a length of $a=254 \mathrm{~mm}$. The stacking sequence, in according with Eq. (1) is expressed as $\left[<T_{0}\left|T_{1}>/<T_{0}\right|-T_{1}>/<-T_{0}\left|T_{1}\right\rangle /<T_{0} \mid-T_{1}>\right]_{4}$. The panel is loaded with a pure compression load and is simply supported, as shown in Fig. 10. The lamina properties are set as follows: $E_{1}=181 \mathrm{GPa}, E_{2}=10.270 \mathrm{GPa}, G_{12}=$ $G_{13}=7.170 \mathrm{GPa}, G_{23}=3.780 \mathrm{GPa}, v_{12}=0.28$, and each ply has a thickness of $0.15 \mathrm{~mm}$.

Three CUF based models with 10B3, 15B3, and 20B3 beam elements have been considered corresponding to 160, 240 and 320 L9 cross-sectional elements, respectively. The results have been compared with a classical FEM model presented in [22]. As reported in Table 2, the CUF model converged with a significantly lower number of DOFs compared to classical FEM model. The convergence of the first six critical loads evaluated with the proposed CUF-based models is presented in Fig. 11. 
Table 1 Linear elastic buckling estimates according to the number of elements through the beam and cross-section

\begin{tabular}{lrrccc}
\hline Model & \multicolumn{1}{c}{ DOF } & 1st Critical Load & 2nd Critical Load & $\mathrm{n}_{\mathrm{z}}{ }^{*}$ & $\mathrm{n}_{\mathrm{x}}{ }^{*}=\mathrm{n}_{\mathrm{y}}{ }^{*}$ \\
\hline \multirow{4}{*}{ Nastran } & 61206 & $1.92 \mathrm{~N}$ & $2.04 \mathrm{~N}$ & - & - \\
& 242406 & $1.85 \mathrm{~N}$ & $2.02 \mathrm{~N}$ & - & - \\
& 964806 & $1.85 \mathrm{~N}$ & $2.02 \mathrm{~N}$ & - & - \\
\hline \multirow{5}{*}{ CUF L9 } & 3969 & $1.91 \mathrm{~N}$ & $2.04 \mathrm{~N}$ & 1 & 10 \\
& 9261 & $1.90 \mathrm{~N}$ & $2.03 \mathrm{~N}$ & 3 & 10 \\
& 17199 & $1.90 \mathrm{~N}$ & $2.03 \mathrm{~N}$ & 6 & 10 \\
& 25137 & $1.90 \mathrm{~N}$ & $2.03 \mathrm{~N}$ & 9 & 10 \\
\hline \multirow{5}{*}{ CUF L9 } & 1089 & $2.13 \mathrm{~N}$ & $2.57 \mathrm{~N}$ & 1 & 5 \\
& 2025 & $1.98 \mathrm{~N}$ & $2.18 \mathrm{~N}$ & 1 & 7 \\
& 3969 & $1.91 \mathrm{~N}$ & $2.04 \mathrm{~N}$ & 1 & 10 \\
& 8649 & $1.87 \mathrm{~N}$ & $1.98 \mathrm{~N}$ & 1 & 15 \\
& 15129 & $1.86 \mathrm{~N}$ & $1.97 \mathrm{~N}$ & 1 & 20 \\
\hline \multirow{6}{*}{ CUF L16 } & 2112 & $1.97 \mathrm{~N}$ & $2.48 \mathrm{~N}$ & 1 & 5 \\
& 3960 & $1.92 \mathrm{~N}$ & $2.14 \mathrm{~N}$ & 1 & 7 \\
& 7812 & $1.88 \mathrm{~N}$ & $2.02 \mathrm{~N}$ & 1 & 10 \\
& 17112 & $1.86 \mathrm{~N}$ & $1.97 \mathrm{~N}$ & 1 & 15 \\
& 30012 & $1.85 \mathrm{~N}$ & $1.96 \mathrm{~N}$ & 1 & 20 \\
\hline
\end{tabular}

$\mathrm{n}_{\mathrm{z}}{ }^{*}=$ number of elements through the thickness

$\mathrm{n}_{\mathrm{x}}{ }^{*}=$ number of elements along the width

$\mathrm{n}_{\mathrm{y}}{ }^{*}=$ number of elements along the beam axis

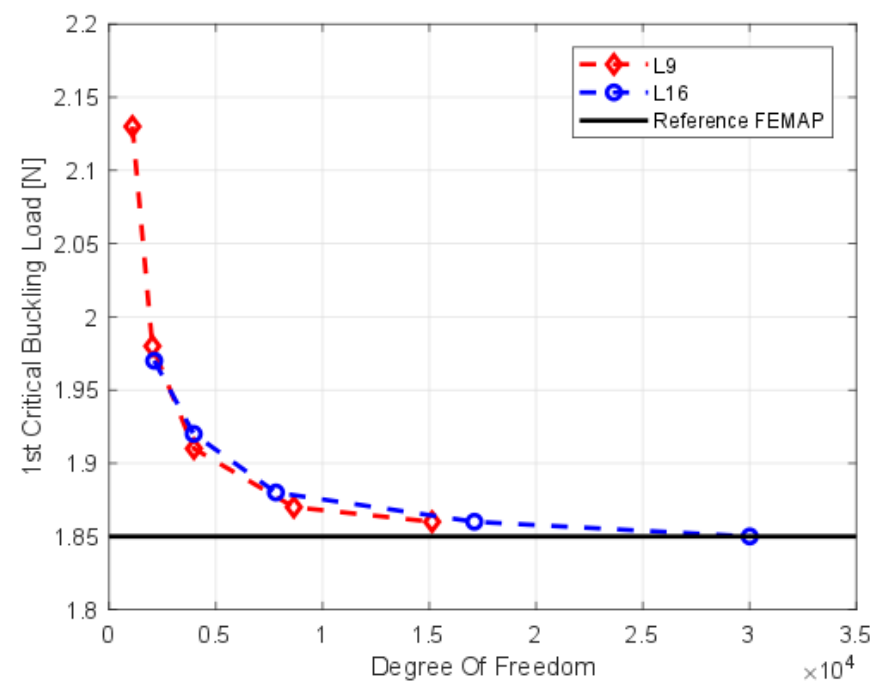

Fig. 8 First critical buckling load vs. DOF, based on the refinement of the beam elements 


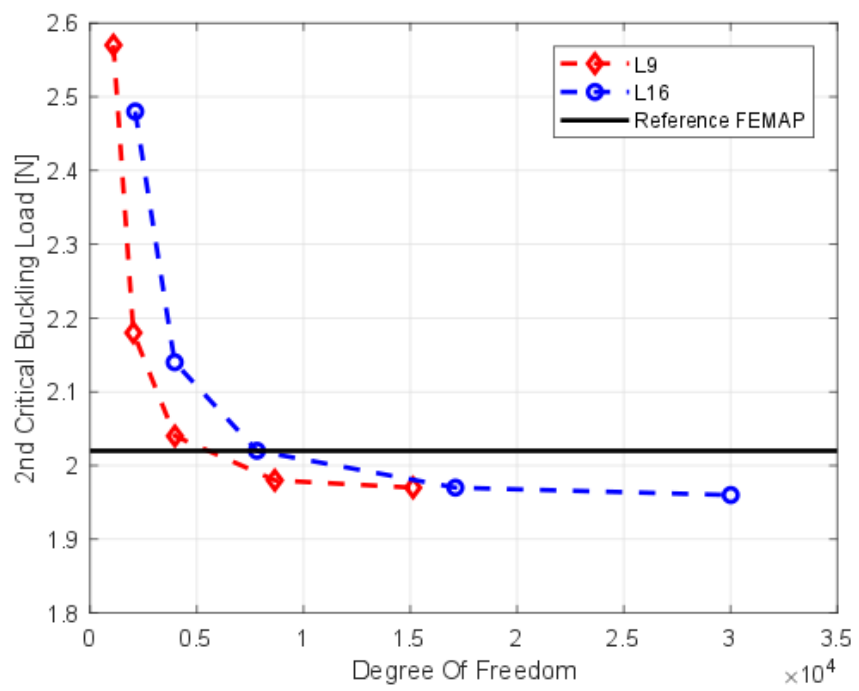

Fig. 9 Second critical buckling load vs. DOF, based on the refinement of the beam element

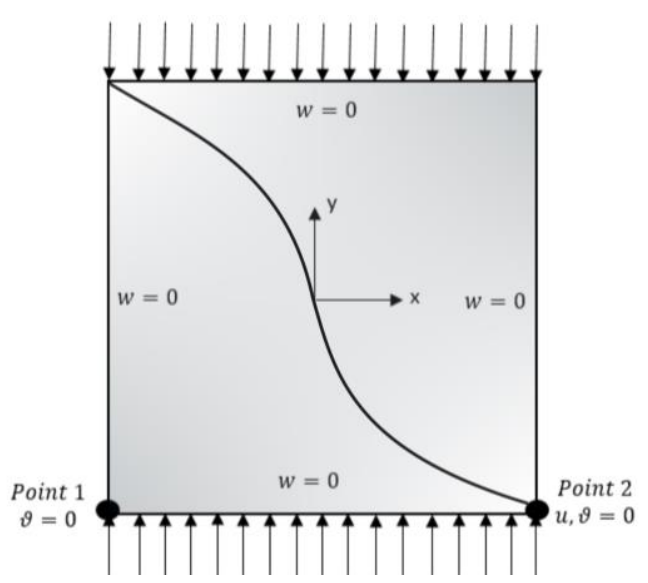

Fig. 10 SSSS boundary condition (BC) of the plate

Table 2 First five critical loads for the sixteen-layer plate $\left[\left\langle 60^{\circ} \mid 15^{\circ}\right\rangle\left\langle 60^{\circ} \mid 15^{\circ}\right\rangle \mid\left\langle-60^{\circ}\right|\right.$ $\left.\left.-15^{\circ}\right\rangle\left\langle 60^{\circ} \mid 15^{\circ}\right\rangle\right]$

\begin{tabular}{lrccccc}
\hline Model & DOF & $\begin{array}{c}\text { Mode 1 } \\
(\mathrm{kN})\end{array}$ & $\begin{array}{c}\text { Mode 2 } \\
(\mathrm{kN})\end{array}$ & $\begin{array}{c}\text { Mode 3 } \\
(\mathrm{kN})\end{array}$ & $\begin{array}{c}\text { Mode 4 } \\
(\mathrm{kN})\end{array}$ & $\begin{array}{c}\text { Mode 5 } \\
(\mathrm{kN})\end{array}$ \\
\hline Ref. [22] & 387205 & 13.62 & 21.62 & 35.40 & 54.46 & 56.01 \\
CUF 10B3 & 43659 & 13.78 & 22.03 & 37.67 & 55.24 & 60.57 \\
CUF 15B3 & 95139 & 13.61 & 21.69 & 35.94 & 54.51 & 57.65 \\
CUF 20B3 & 166419 & 13.67 & 21.68 & 35.69 & 54.60 & 56.69 \\
\hline
\end{tabular}




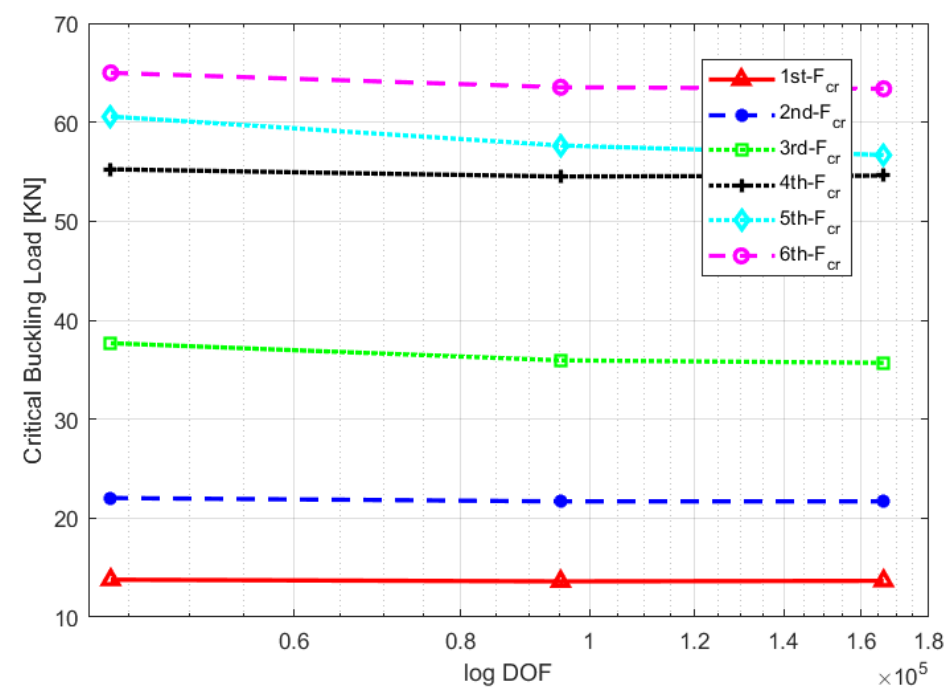

Fig. 11 Convergence of the first six critical loads using different CUF-based models

Pre-buckling and buckling analyses considering various stacking sequences were performed in order to determine non-uniform stress distributions due to the in-plane load and their effects on the critical loads. Herein, $T_{0}$ is a fixed angle, and $T_{1}$ increases from $0^{\circ}$ to $90^{\circ}$ in steps of $\pi / 15$, as reported in Table 3. The model with 10B3 elements is considered.

Table 3 Different lay-up considered for the laminate

\begin{tabular}{ccc}
\hline Lay-up & \multicolumn{2}{c}{ Stacking sequence } \\
& {$\left[\left\langle\mathrm{T}_{0}{ }^{\circ} \mid \mathrm{T}_{1}{ }^{\circ}\right\rangle\left|\left\langle-\mathrm{T}_{0}{ }^{\circ} \mid \mathrm{T}_{1}{ }^{\circ}\right\rangle\right|\left\langle-\mathrm{T}_{0}{ }^{\circ} \mid-\mathrm{T}_{1}{ }^{\circ}\right\rangle \mid\left\langle\mathrm{T}_{0}{ }^{\circ} \mid \mathrm{T}_{1}{ }^{\circ}\right\rangle\right]_{4}$} \\
\cline { 2 - 3 }$T_{0}{ }^{\circ}$ & $T_{1}{ }^{\circ}$ \\
\hline 1 & 60 & 0 \\
2 & 60 & 15 \\
3 & 60 & 30 \\
4 & 60 & 45 \\
5 & 60 & 60 \\
6 & 60 & 75 \\
7 & 60 & 90 \\
\hline
\end{tabular}

Table 4 reports the displacements fields and the normal in-plane stresses of some of the stacking sequences considered. Table 5 shows the first five critical buckling modes and the related critical load values for all the lamination schemes considered.

The results demonstrate that curvilinear fiber paths can be used to modify the in-plane stress distributions. Non-uniform stress fields can be obtained although the panel is subject to a constant uniaxial compression.

In the buckling case, as shown in Table 5 , the variation of fiber orientations, $T_{1}$, and the resulting change in the stress field lead to significant changes in the critical buckling loads and their modal shapes. 
For instance, increasing $T_{1}$ from $0^{\circ}$ to $45^{\circ}$, the first critical load increases by $47.64 \%$, while, for a lamination angle, $T_{1}$, higher than $45^{\circ}$, the first mode to appear has two halfwaves instead of one in the direction of the applied load. Fig. 12 reports the values of the first six critical loads with the variation of lamination angle $T_{1}$.

These results demonstrate that the proposed CUF model can be used to evaluate the complex stress fields resulting from the use of VAT laminas, that is, this approach provides an accurate prediction of the geometric stiffness and critical loads of such complex structures. To validate further the performances of the present model the free vibration of VAT laminates is considered in the following section.

Table 4 Pre-buckling displacement and stress distribution for some of the staking sequences considered. The stress fields have been evaluated at the top of the plate.

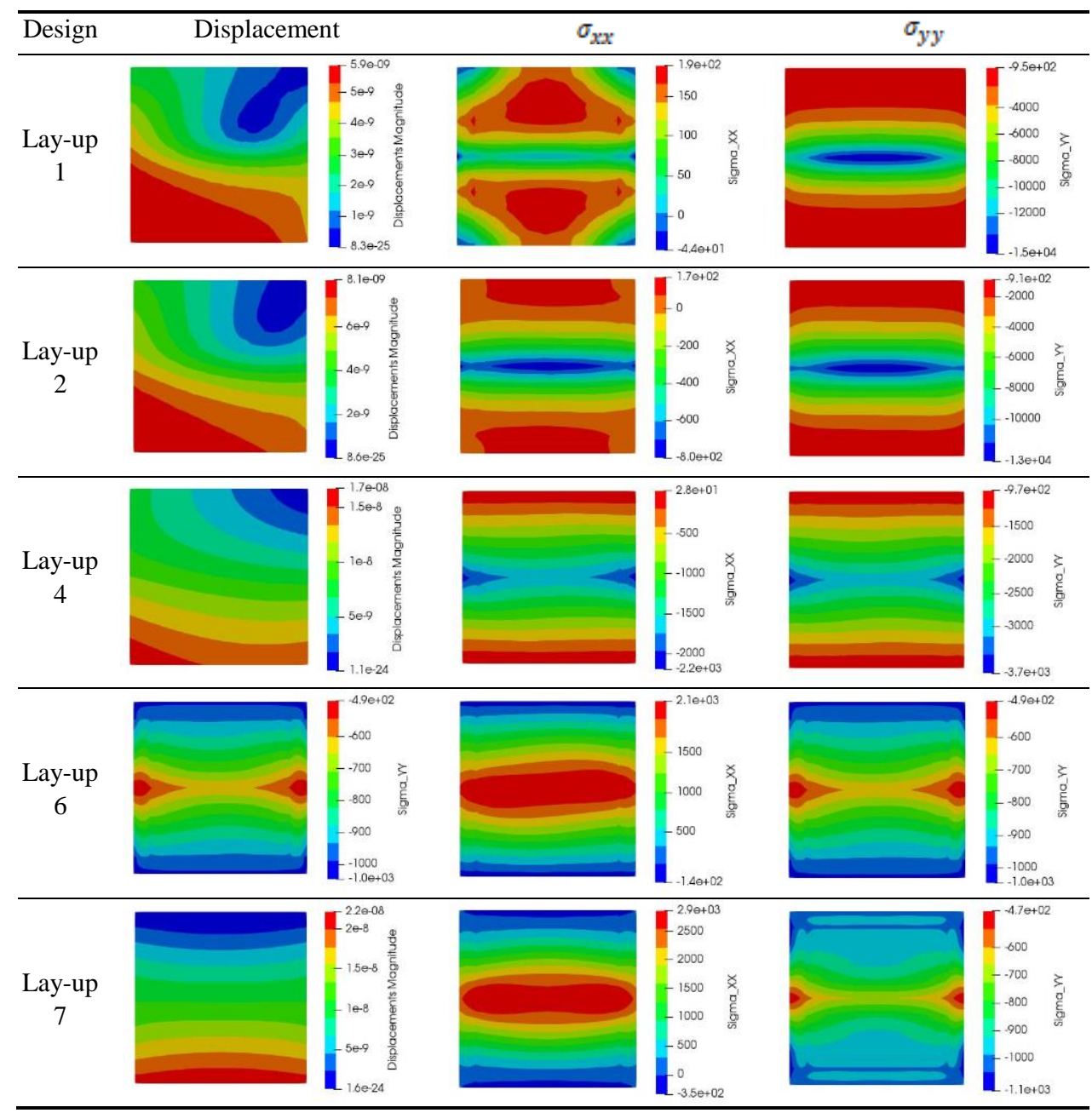


Effect of Fiber Orientation Path on the Buckling-Free Vibration, and Static Analyses of Variable Angle... 179

Table 5 First six critical loads and modal shapes

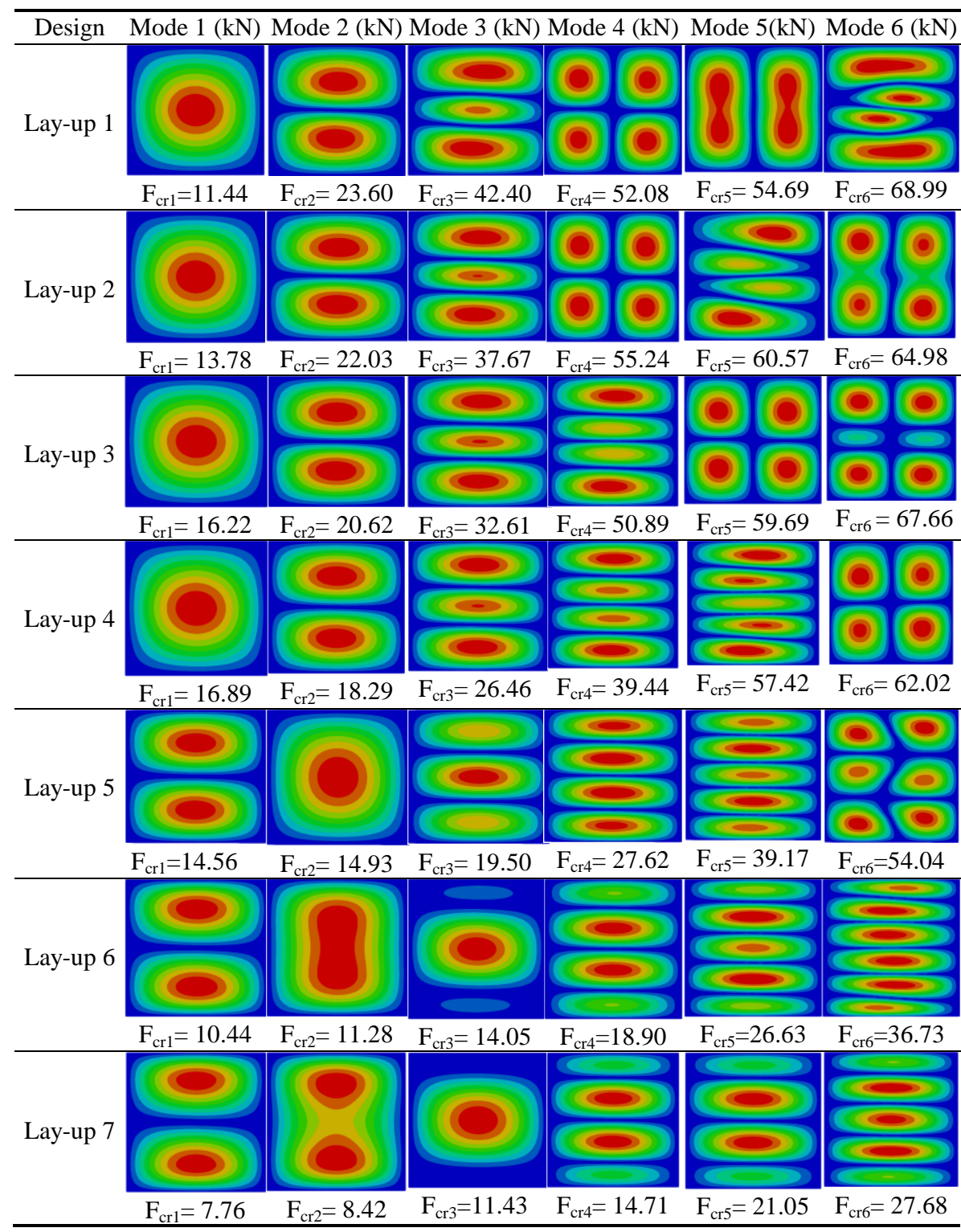




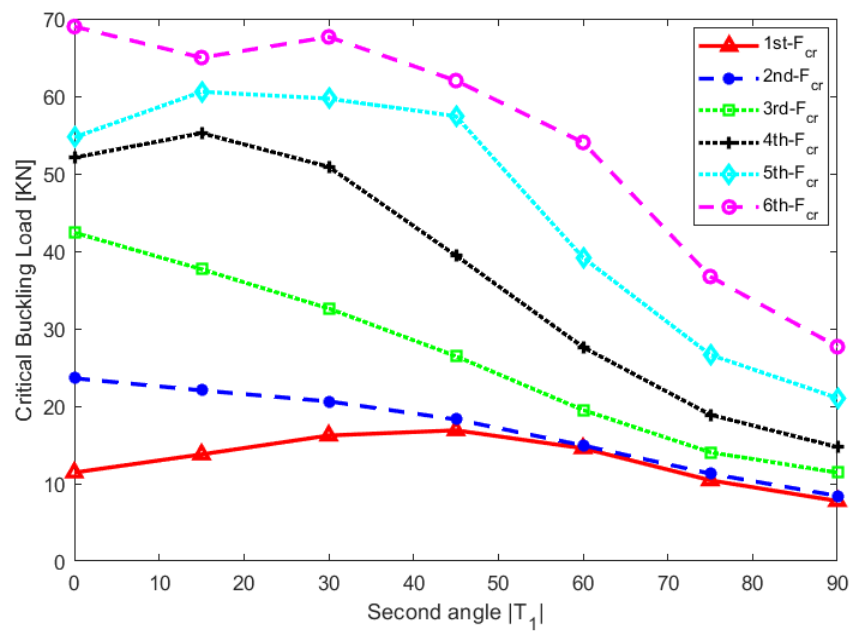

Fig. 12 First six critical buckling loads for different $T_{1}$ values

\subsection{Free vibration analysis of a sixteen-layer VAT plate}

In this section, the free-vibration response of a VAT panel has been investigated considering different geometries and boundary conditions, see Eq. 19. Various stacking sequences see Table 3, have been considered. Two different geometries have been used: square and rectangle plates with $a / t=105.85$ and $a / t=52.92 \quad(a=0.254, b=0.127 \mathrm{~m})$, as shown in Figs. 14 (up) and 14 (down), respectively.

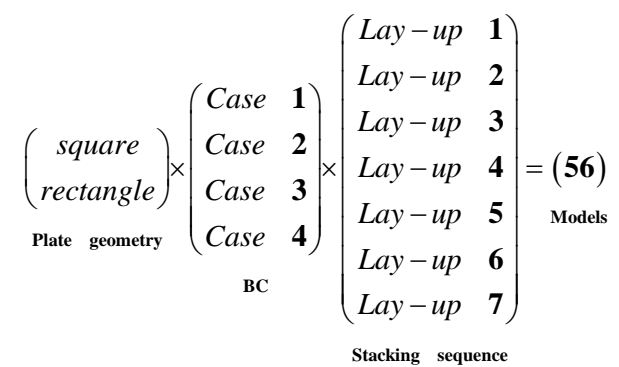




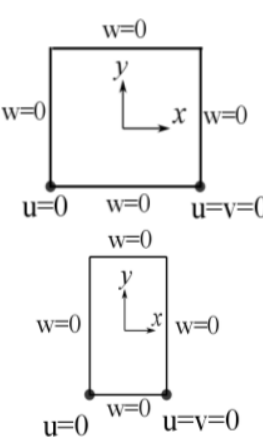

Case 1
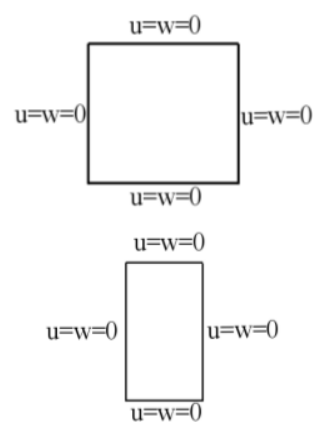

Case 2
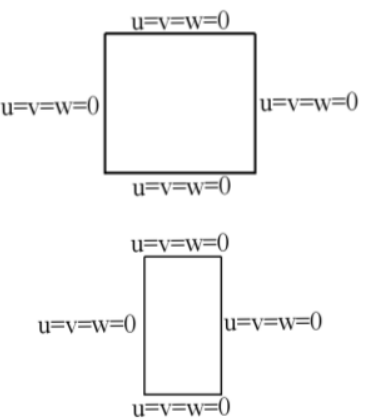

Case 3
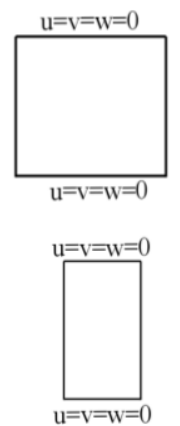

Case 4

Fig. 14 Four-edge plates subjected to four different BCs, case 1 (SSSS), case 2 (SSSS-I), case 3 (CCCC) and case 4 (CFCF)

The first six natural frequencies for the square and rectangle geometries for various BCs are summarized in Tables 6 to 9 .

The results for case 1 (SSSS), as described in Table 6 and Fig. 15, indicate that when the square panel is considered the first natural frequency exhibits a growth of $14.57 \%$ with an increase of $T_{1}$ from $0^{\circ}$ to $45^{\circ}$, whereas in lay-ups 5,6 , and $7\left(T_{1}\right.$ from $60^{\circ}$ to $\left.90^{\circ}\right)$ the first frequency values decrease by $16.47 \%$. In contrast, in the rectangular panel, with the increase in the $T_{1}$ angle from $0^{\circ}$ to $90^{\circ}$, the first frequencies increase by $71.91 \%$. The natural frequencies obtained for cases 2 (SSSS-I) and 3 (CCCC) are listed in Tables 7 and 8, respectively. Figs.16 and 17 show that the variation of $T_{1}$ results in similar effects on natural frequencies when cases 1, 2 and 3 are considered. However, in case 4 (CFCF) the results indicate that when the square plate is considered, an increase in the fiber orientation angles $\left(T_{1}\right)$ leads to an increase of $130.96 \%$ in the first natural frequency values, see Tab. 9 and Fig. 18. These findings demonstrate that the frequency behaviors are strongly dependent on the geometry, boundary conditions, and stacking sequence designs. The large design space coming from the use of VAT composite materials makes it possible to optimize the staking sequence exceeding the performance normally obtained by classic composite materials.

Table 6 First six natural frequencies for case 1 - SSSS

\begin{tabular}{ccccccrr}
\hline a/h & Design & Mode 1 & Mode 2 & Mode 3 & Mode 4 & Mode 5 & Mode 6 \\
\hline \multirow{6}{*}{$=105.85$} & Lay-up 1 & 229.50 & 537.07 & 659.99 & 838.68 & 945.24 & 1026.53 \\
& Lay-up 2 & 246.31 & 590.42 & 635.41 & 911.18 & 984.15 & 1149.90 \\
& Lay-up 3 & 260.17 & 591.19 & 656.93 & 948.65 & 1016.47 & 1131.57 \\
& Lay-up 4 & 262.96 & 551.92 & 688.61 & 961.98 & 983.72 & 1048.42 \\
& Lay-up 5 & 252.34 & 495.98 & 701.96 & 859.34 & 946.74 & 1009.32 \\
& Lay-up 6 & 230.86 & 428.17 & 702.29 & 728.86 & 870.24 & 948.18 \\
& Lay-up 7 & 210.77 & 372.97 & 635.35 & 703.71 & 769.15 & 893.22 \\
\hline \multirow{6}{*}{52.92} & Lay-up 1 & 897.56 & 1332.14 & 2051.60 & 2193.36 & 2323.23 & 3304.48 \\
& Lay-up 2 & 988.30 & 1402.41 & 2159.78 & 2303.63 & 2393.00 & 3454.18 \\
& Lay-up 3 & 1125.46 & 1500.44 & 2338.30 & 2550.20 & 2747.62 & 3392.48 \\
& Lay-up 4 & 1259.12 & 1576.96 & 2228.99 & 3060.88 & 3136.75 & 3339.63 \\
& Lay-up 5 & 1379.00 & 1638.24 & 2057.49 & 2645.51 & 3431.71 & 3615.06 \\
& Lay-up 6 & 1479.00 & 1702.01 & 1923.68 & 2291.65 & 2830.93 & 3593.33 \\
& Lay-up 7 & 1543.10 & 1758.48 & 1916.83 & 2249.48 & 2754.41 & 3436.64 \\
\hline
\end{tabular}


Table 7 First six natural frequencies for case 2 - SSSS-I

\begin{tabular}{ccrrrrrr}
\hline $\mathrm{a} / \mathrm{h}$ & Design & \multicolumn{1}{c}{ Mode 1 } & Mode 2 & Mode 3 & Mode 4 & Mode 5 & Mode 6 \\
\hline \multirow{6}{*}{$=105.85$} & Lay-up 1 & 485.38 & 898.62 & 1019.77 & 1389.39 & 1521.14 & 1824.45 \\
& Lay-up 2 & 483.44 & 935.55 & 974.59 & 1401.63 & 1636.83 & 1697.43 \\
& Lay-up 3 & 470.75 & 885.60 & 984.91 & 1392.64 & 1533.39 & 1747.67 \\
& Lay-up 4 & 452.97 & 800.44 & 1011.30 & 1321.94 & 1396.73 & 1847.50 \\
& Lay-up 5 & 436.04 & 716.54 & 1034.19 & 1150.35 & 1357.23 & 1748.45 \\
& Lay-up 6 & 424.72 & 650.46 & 1004.93 & 1055.29 & 1326.70 & 1508.17 \\
& Lay-up 7 & 420.64 & 611.19 & 914.40 & 1076.54 & 1307.15 & 1357.56 \\
\hline \multirow{6}{*}{52.92} & Lay-up 1 & 897.16 & 1330.80 & 2050.53 & 2190.15 & 2321.18 & 3298.19 \\
& Lay-up 2 & 987.92 & 1401.45 & 2158.27 & 2301.56 & 2390.72 & 3450.16 \\
& Lay-up 3 & 1125.45 & 1500.43 & 2338.29 & 2550.18 & 2747.59 & 3392.46 \\
& Lay-up 4 & 1258.87 & 1576.27 & 2227.66 & 3058.72 & 3135.22 & 3337.48 \\
& Lay-up 5 & 1378.90 & 1637.87 & 2056.67 & 2643.98 & 3429.08 & 3614.83 \\
& Lay-up 6 & 1479.00 & 1702.01 & 1923.67 & 2291.64 & 2830.92 & 3593.32 \\
& Lay-up 7 & 1543.09 & 1758.35 & 1916.47 & 2248.80 & 2753.17 & 3434.61 \\
\hline
\end{tabular}

Table 8 First six natural frequencies for case 3 - CCCC

\begin{tabular}{ccrrrrrr}
\hline a/h & Design & \multicolumn{1}{c}{ Mode 1 } & Mode 2 & Mode 3 & Mode 4 & Mode 5 & Mode 6 \\
\hline \multirow{6}{*}{$=105.85$} & Lay-up 1 & 485.52 & 899.09 & 1020.00 & 1390.14 & 1522.16 & 1824.80 \\
& Lay-up 2 & 483.66 & 936.15 & 975.06 & 1402.73 & 1638.32 & 1698.27 \\
& Lay-up 3 & 471.05 & 886.28 & 985.77 & 1394.25 & 1534.78 & 1749.73 \\
& Lay-up 4 & 453.29 & 801.14 & 1012.23 & 1323.38 & 1398.49 & 1849.72 \\
& Lay-up 5 & 436.28 & 717.03 & 1034.96 & 1151.26 & 1358.57 & 1750.10 \\
& Lay-up 6 & 424.89 & 650.70 & 1005.31 & 1055.87 & 1327.43 & 1508.77 \\
& Lay-up 7 & 420.77 & 611.32 & 914.56 & 1076.99 & 1307.54 & 1357.76 \\
\hline \multirow{6}{*}{52.92} & Lay-up 1 & 898.47 & 1333.59 & 2053.71 & 2195.50 & 2326.34 & 3307.40 \\
& Lay-up 2 & 989.23 & 1403.79 & 2161.57 & 2306.00 & 2395.29 & 3456.95 \\
& Lay-up 3 & 1126.72 & 1502.21 & 2341.32 & 2553.10 & 2751.29 & 3396.34 \\
& Lay-up 4 & 1260.92 & 1579.44 & 2232.79 & 3066.07 & 3141.84 & 3346.17 \\
& Lay-up 5 & 1380.96 & 1640.75 & 2060.86 & 2649.94 & 3437.33 & 3620.55 \\
& Lay-up 6 & 1480.54 & 1703.27 & 1924.99 & 2293.35 & 2833.02 & 3595.84 \\
& Lay-up 7 & 1544.27 & 1759.09 & 1917.67 & 2250.82 & 2755.95 & 3438.23 \\
\hline
\end{tabular}

Table 9 First six natural frequencies for case 4 - CFCF

\begin{tabular}{ccrrrrrr}
\hline $\mathrm{a} / \mathrm{h}$ & Design & \multicolumn{1}{c}{ Mode 1 } & Mode 2 & Mode 3 & Mode 4 & Mode 5 & Mode 6 \\
\hline \multirow{5}{*}{$=105.85$} & Lay-up 1 & 168.47 & 221.02 & 438.20 & 467.69 & 496.24 & 819.45 \\
& Lay-up 2 & 191.95 & 251.97 & 508.91 & 510.87 & 574.94 & 938.46 \\
& Lay-up 3 & 226.63 & 290.17 & 544.89 & 618.04 & 685.38 & 928.32 \\
& Lay-up 4 & 271.46 & 332.93 & 560.23 & 753.28 & 822.39 & 895.22 \\
& Lay-up 5 & 321.29 & 378.61 & 552.72 & 830.02 & 897.86 & 974.37 \\
& Lay-up 6 & 364.45 & 418.01 & 527.06 & 738.07 & 1008.61 & 1061.33 \\
& Lay-up 7 & 389.11 & 437.02 & 495.56 & 653.91 & 929.14 & 1064.60 \\
\hline \multirow{5}{*}{52.92} & Lay-up 1 & 715.46 & 825.44 & 1217.10 & 1748.81 & 1862.21 & 1990.40 \\
& Lay-up 2 & 547.99 & 575.96 & 1075.40 & 1420.49 & 1440.48 & 1531.47 \\
& Lay-up 3 & 579.07 & 597.58 & 1151.93 & 1440.75 & 1456.42 & 1519.91 \\
& Lay-up 4 & 846.73 & 871.56 & 1375.78 & 1743.31 & 2205.91 & 2211.32 \\
& Lay-up 5 & 1276.64 & 1331.63 & 1529.77 & 1842.07 & 2269.04 & 2825.54 \\
& Lay-up 6 & 1477.97 & 1634.49 & 1683.48 & 1791.30 & 1993.34 & 2321.45 \\
& Lay-up 7 & 1500.65 & 1497.18 & 1554.01 & 1812.39 & 2028.78 & 2381.92 \\
\hline
\end{tabular}



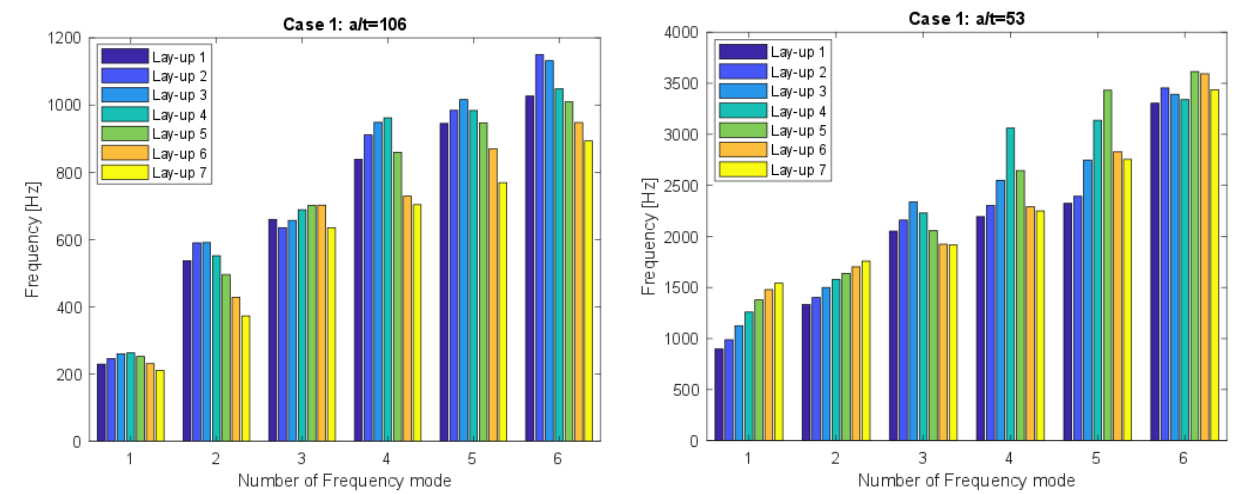

Fig. 15 Sensitivity of the first six frequencies, BC case 1 for different fiber orientations $T_{1}$
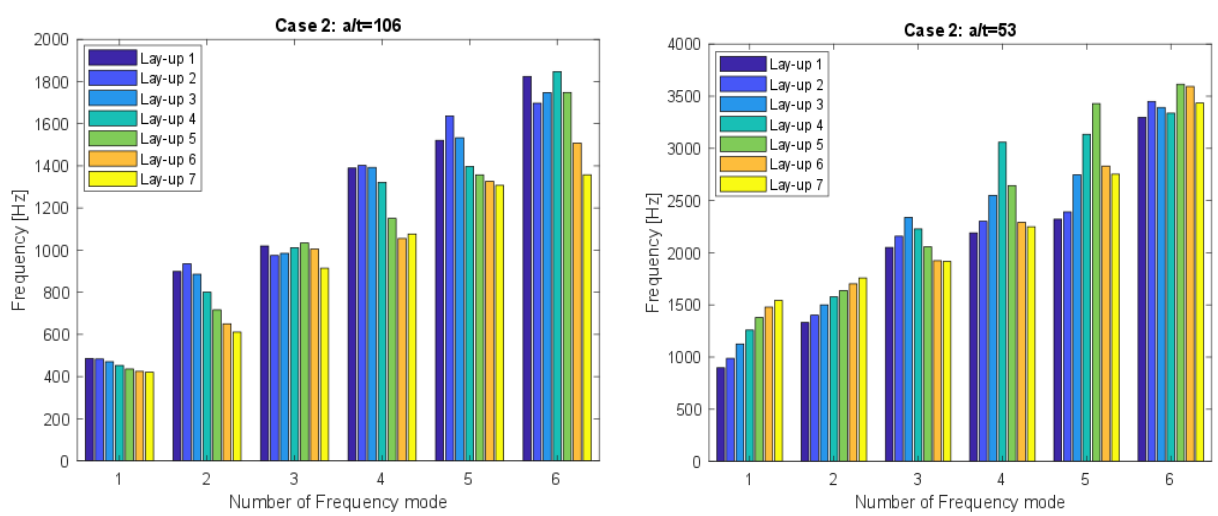

Fig. 16 Sensitivity of the first six frequencies, BC case 2 for different fiber orientations $T_{1}$
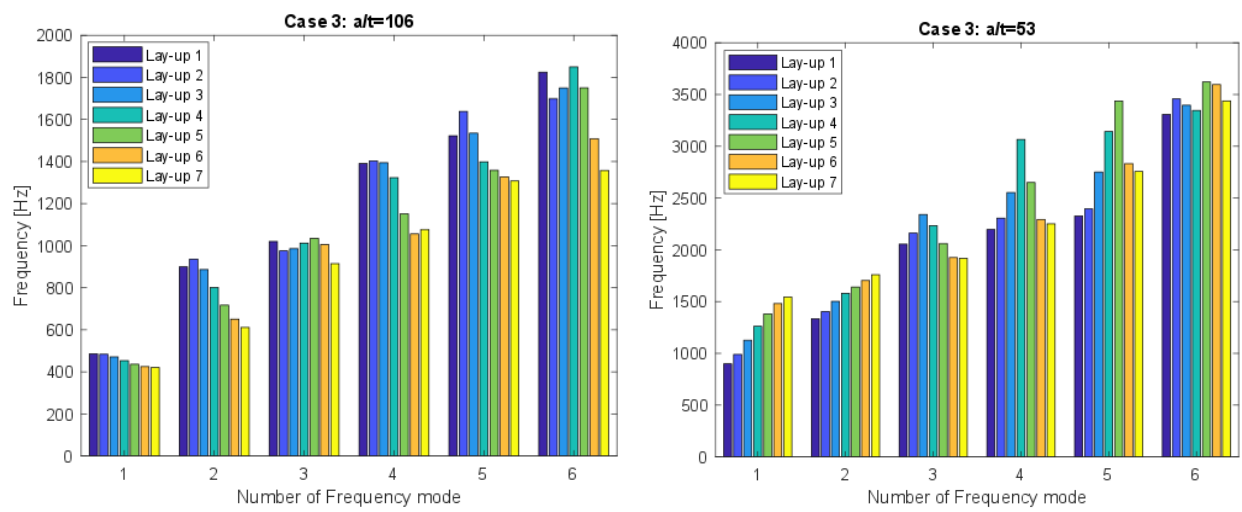

Fig. 17 Sensitivity of the first six frequencies, BC case 3 for different fiber orientations $T_{1}$ 

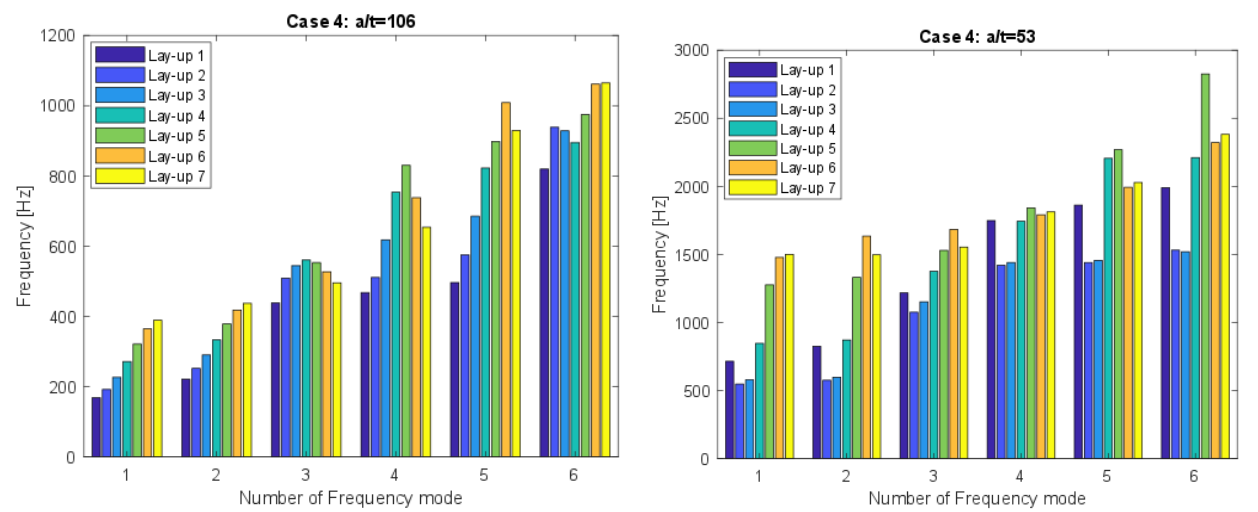

Fig. 18 Sensitivity of the first six frequency, BC case 4 for different fiber orientations $T 1$

\subsection{Trade-off analysis}

Identifying the best lamination strategy requires a compromise to fulfill the design requirements in each operational scenario: static, dynamic or buckling. In this section, a preliminary trade-off analysis is performed using the results shown previously.

The results of the performed linear buckling, free vibration and static analyses are compared considering the lamination strategies reported in Table 3. The fully simply supported boundary condition is used. The results of the buckling analysis are obtained from Table 5 corresponding to the boundary condition shown in Fig. 10. The results of the natural frequencies for the different VAT lay-up schemes were considered based on Table 6 where a fully simply supported square plate is investigated. In the case of static analysis, a transverse uniform pressure has been applied to the simply supported panel.

To investigate the effect of different lay-up designs of the VAT a weighted index has been introduced. The critical buckling loads, natural frequencies and maximum displacement are considered. The normalization in these cases corresponds to the scaling of a variable to have a positive value greater than 0 or a maximum value of 1 . Consequently, each value includes a weight during the evaluation, as follows:

$$
I_{w}=1-\left(\frac{X_{\max }-X_{i}}{X_{\max }}\right)=\frac{X_{i}}{X_{\max }}, 0<\frac{X_{i}}{X_{\max }} \leqslant 1
$$

where $I_{w}$ is introduced as a weighted index for the various analyses, and $\mathrm{X}_{\max }$ denotes the maximum value of $\mathrm{X}_{\mathrm{i}}$ for each variable in every individual lay-up design.

The results for the three analyses are presented in Table 10. For both the buckling and free-vibration analyses, the minimum weighted index values correspond to lay-up 7 . In Table 10, the sum of all the weighted indexes is presented for each lay-up design to evaluate the performance of each fiber orientation angle. In addition, the mean values, and percentages of all the weighted indexes are summarized.

Considering the buckling modes, lay-up 2 exhibits the highest percentage of $93 \%$ among those of all the other lay-up designs. Lay-ups 2, 3 and 4 appear as the optimal designs in both the buckling and free-vibration analyses. In terms of the static behavior, the optimal 
models for the VAT lay-ups are different. Lay-up 1 provides the best compromise among the set-up considered since it can keep a percentage higher than $90 \%$ in all the analyses considered.

The results indicate that the buckling analysis is more sensitive to the change in the fiber angle orientation compared to the other two analyses. The mean value of the buckling load indexes ranges from $5 \%$ to $93 \%$ of the maximum value. The displacement obtained in the static analysis ranges from $68 \%$ to $100 \%$ of the maximum value. Finally, the mean value of the natural frequency indexes ranges from $76 \%$ to $98 \%$.

Table 10 Weighted indexes for evaluating the lay-up schemes

\begin{tabular}{|c|c|c|c|c|c|c|c|c|}
\hline $\begin{array}{l}\text { Type of } \\
\text { analysis }\end{array}$ & & & & $\mathrm{I}_{\mathrm{w}}$ & & & & \\
\hline \multirow{10}{*}{$\begin{array}{c}\text { Free- } \\
\text { vibration } \\
\text { analysis }\end{array}$} & Modes & Lay-up 1 & Lay-up 2 & Lay-up 3 & Lay-up 4 & Lay-up 5 & Lay-up 6 & Lay-up 7 \\
\hline & Mode 1 & 0.87 & 0.94 & 0.99 & 1.00 & 0.96 & 0.88 & 0.80 \\
\hline & Mode 2 & 0.91 & 1.00 & 1.00 & 0.93 & 0.84 & 0.72 & 0.63 \\
\hline & Mode 3 & 0.94 & 0.90 & 0.94 & 0.98 & 1.00 & 1.00 & 0.90 \\
\hline & Mode 4 & 0.87 & 0.95 & 0.99 & 1.00 & 0.89 & 0.76 & 0.73 \\
\hline & Mode 5 & 0.93 & 0.97 & 1.00 & 0.97 & 0.93 & 0.86 & 0.76 \\
\hline & Mode 6 & 0.89 & 1.00 & 0.98 & 0.91 & 0.88 & 0.82 & 0.78 \\
\hline & Sum & 5.42 & 5.76 & 5.90 & 5.79 & 5.50 & 5.04 & 4.60 \\
\hline & Mean & 0.90 & 0.96 & 0.98 & 0.97 & 0.92 & 0.84 & 0.77 \\
\hline & Percent $(\%)$ & 90.26 & 95.93 & 98.25 & 96.56 & 91.68 & 84.01 & 76.70 \\
\hline \multirow{9}{*}{$\begin{array}{c}\text { Critical } \\
\text { buckling load }\end{array}$} & Mode 1 & 0.68 & 0.82 & 0.96 & 1.00 & 0.86 & 0.62 & 0.46 \\
\hline & Mode 2 & 1.00 & 0.93 & 0.87 & 0.78 & 0.63 & 0.48 & 0.36 \\
\hline & Mode 3 & 1.00 & 0.89 & 0.77 & 0.62 & 0.46 & 0.33 & 0.27 \\
\hline & Mode 4 & 0.94 & 1.00 & 0.92 & 0.71 & 0.50 & 0.34 & 0.27 \\
\hline & Mode 5 & 0.90 & 1.00 & 0.99 & 0.95 & 0.65 & 0.44 & 0.35 \\
\hline & Mode 6 & 1.00 & 0.94 & 0.98 & 0.90 & 0.78 & 0.53 & 0.40 \\
\hline & Sum & 5.52 & 5.58 & 5.49 & 4.96 & 3.88 & 2.74 & 2.10 \\
\hline & Mean & 0.92 & 0.93 & 0.91 & 0.83 & 0.65 & 0.46 & 0.35 \\
\hline & Percent $(\%)$ & 92.05 & 93.00 & 91.50 & 82.67 & 64.74 & 45.69 & 35.01 \\
\hline \multirow{4}{*}{$\begin{array}{c}\text { Static } \\
\text { structural } \\
\text { analysis }\end{array}$} & $\begin{array}{c}\text { Max- } \\
\text { displacement }\end{array}$ & 0.92 & 0.79 & 0.71 & 0.69 & 0.74 & 0.86 & 1.00 \\
\hline & Sum & 0.92 & 0.79 & 0.71 & 0.69 & 0.74 & 0.86 & 1.00 \\
\hline & Mean & 0.92 & 0.79 & 0.71 & 0.69 & 0.74 & 0.86 & 1.00 \\
\hline & Percent (\%) & 91.78 & 79.45 & 70.94 & 68.91 & 73.69 & 85.76 & 100.00 \\
\hline
\end{tabular}

\section{CONCLUSIONS}

In this work, buckling, free-vibration, and static response analyses of VAT laminates were performed under the CUF framework. A one-dimensional CUF beam theory was used, and a layer-wise approach was adopted as cross-sectional kinematic. The spatial variation of the fiber orientation has been described in a rigorous manner with a smooth and continuous variation of the panel stiffness. Different lay-up was considered to reveal the effects of the use of curvilinear fibers on the static, buckling and free vibration response of a square symmetric VAT plate. The results have been compared with those presented in literature and with classical FEM models. 
A preliminary convergence analysis was conducted to assess the present computational model. The results show the computational efficiency of the current approach that can ensure an accurate prediction of the critical loads with a fraction of the computational cost required by classical FEM models.

The parametric analysis of a sixteen-layer panel was conducted to study the effects resulting from the variation of the lamination parameters. Static, buckling and free-vibration analyses were conducted. The results show that VAT lamination schemes can be used to redistribute the in-plane normal stress fields, that is, the critical buckling loads can be modified to fulfill the design requirements. The free vibration analyses have pointed out that different lay-ups led to a variation of the dynamic response of the structure. The effectiveness of the VAT depends on the geometry and boundary conditions of the structure.

In conclusion, the results pointed out that the use of VAT laminates gives the possibility to obtain optimal designs that can satisfy strict requirements. Nevertheless, the large number of design variables requires a significant computational effort to identify the most promising configurations, that is, efficient computational models are mandatory. The high accuracy and computational efficiency make the present approach suitable for future applications in the design and optimization of VAT composites.

\section{REFERENCES}

1. Gürdal, Z., Tatting, BF., Wu, C., 2008, Variable stiffness composite panels: effects of stiffness variation on the in-plane and buckling response, Composites Part A: Applied Science and Manufacturing, 39(5), pp. 911-22.

2. Olmedo, R., Gurdal, Z., 1993, Buckling response of laminates with spatially varying fiber orientations, 34th Structures Structural Dynamics and Materials Conference, La Jolla, CA, U.S.A

3. Ijsselmuiden, S.T., Abdalla, M.M., Gurdal, Z., 2010, Optimization of variable-stiffness panels for maximum buckling load using lamination parameters, AIAA journal, 48(1), pp. 134-43.

4. Jones RM., 2014, Mechanics of Composite Materials, CRC press.

5. Liu, D., Toropov, V.V., Barton, D.C., Querin, O.M., 2015, Weight and mechanical performance optimization of blended composite wing panels using lamination parameters, Structural and Multidisciplinary Optimization, 52(3), pp. 549-562.

6. Kizaki, T., Fujii, T., Iwama, M., Shiraishi, M., Sugita, N., Ahn, S.-H., 2018, Design of a CFRP-elastomer composite with high stiffness and damping capability, CIRP Annals, 67(1), pp. 413-418.

7. Albazzan, M.A., Harik, R., Tatting, B.F., Gürdal, Z., 2019, Efficient design optimization of nonconventional laminated composites using lamination parameters: A state of the art, Composite Structures, 209, pp. 362-374.

8. Gurdal, Z., Olmedo, R., 1993, In-plane response of laminates with spatially varying fiber orientations-variable stiffness concept, AIAA journal, 31(4), pp. 751-758.

9. Alhajahmad, A., Abdalla, M.M., Gürdal, Z., 2008, Design tailoring for pressure pillowing using tow-placed steered fibers, Journal of Aircraft, 45(2), pp. 630-640.

10. Hyer, M.W., Lee, H., 1991, The use of curvilinear fiber format to improve buckling resistance of composite plates with central circular holes, Composite structures, 18(3), pp. 239-61.

11. Wu, Z., Raju, G., Weaver, P.M., 2015, Framework for the buckling optimization of variable-angle tow composite plates, AIAA Journal, 53(12), pp. 3788-3804.

12. Setoodeh, S., Abdalla, M.M., Ijsselmuiden, S.T., Gürdal, Z., 2009, Design of variable-stiffness composite panels for maximum buckling load, Composite structures, 87(1), pp. 109-117.

13. Weaver, P., Potter, K., Hazra, K., Saverymuthapulle, M., Hawthorne, M., 2009, Buckling of variable angle tow plates: from concept to experiment, 50th AIAA/ASME/ASCE/AHS/ASC structures, structural dynamics, and materials conference 17th AIAA/ASME/AHS adaptive structures conference, Palm Springs, California.

14. Rouhi, M., Ghayoor, H., Hoa, S.V., Hojjati, M., 2014, Multi-step design optimization of variable stiffness composite cylinders made by fiber steering, Proceedings of the American Society for Composites-29th Technical Conference, La Jolla, CA, USA. 
15. Ghayoor, H., Rouhi, M., Hoa, S.V., Hojjati, M., 2017, Use of curvilinear fibers for improved bending-induced buckling capacity of elliptical composite cylinders, International Journal of Solids and Structures, 109, pp. $112-122$.

16. Baseri, V., Jafari, G.S., Kolahchi, R., 2016, Analytical solution for buckling of embedded laminated plates based on higher order shear deformation plate theory, Steel Compos Struct, 21(4), pp. 883-919.

17. Meziane, M.A.A., Abdelaziz, H.H., Tounsi, A., 2014, An efficient and simple refined theory for buckling and free vibration of exponentially graded sandwich plates under various boundary conditions, Journal of Sandwich Structures \& Materials, 16(3), pp. 293-318.

18. Tang, Y., Wang, X., 2011, Buckling of symmetrically laminated rectangular plates under parabolic edge compressions, International Journal of Mechanical Sciences, 53(2), pp. 91-97.

19. Lopes, C., Gürdal, Z., Camanho, P., 2008, Variable-stiffness composite panels: Buckling and first-ply failure improvements over straight-fibre laminates, Computers \& Structures, 86(9), pp. 897-907.

20. Jana, P., Bhaskar, K., 2006, Stability analysis of simply-supported rectangular plates under non-uniform uniaxial compression using rigorous and approximate plane stress solutions, Thin-Walled Structures, 44(5), pp. 507-516.

21. Raju, G., Wu, Z., Weaver, P.M., 2015, Buckling and postbuckling of variable angle tow composite plates under in-plane shear loading, International Journal of Solids and Structures, 58, pp. 270-287.

22. Hao, P., Yuan, X., Liu, H., Wang, B., Liu, C., Yang, D., et al., 2017, Isogeometric buckling analysis of composite variable-stiffness panels, Composite Structures, 165, pp. 192-208.

23. Hachemi, M., Hamza-Cherif, S., Houmat, A., 2020, Free vibration analysis of variable stiffness composite laminate plate with circular cutout, Australian Journal of Mechanical Engineering, 18(1), pp. 63-79.

24. Stodieck, O., Cooper, J.E., Weaver, P.M., Kealy, P., 2013, Improved aeroelastic tailoring using tow-steered composites. Composite Structures, 106, pp. 703-715.

25. Zhao, W., Kapania, R.K., 2019, Prestressed vibration of stiffened variable-angle tow laminated plates, AIAA Journal, 57(6), pp. 2575-2593.

26. Honda, S., Narita, Y., 2011, Vibration design of laminated fibrous composite plates with local anisotropy induced by short fibers and curvilinear fibers, Composite Structures, 93(2), pp. 902-910.

27. Akhavan, H., Ribeiro, P., 2011, Natural modes of vibration of variable stiffness composite laminates with curvilinear fibers, Composite Structures, 93(11), pp. 3040-3047.

28. Labans, E., Bisagni, C., 2019, Buckling and free vibration study of variable and constant-stiffness cylindrical shells, Composite Structures, 210, pp. 446-457.

29. Samukham, S., Raju, G., Vyasarayani, C., 2017, Parametric instabilities of variable angle tow composite laminate under axial compression, Composite Structures, 166, pp. 229-238.

30. Samukham, S., Vyasarayani, C., Raju, G., 2020, Implicit Floquet analysis for parametric instabilities in a variable angle tow composite panel, Composite Structures, 233, 111637.

31. Samukham, S., Raju, G., Vyasarayani, C., Weaver, P.M., 2019, Dynamic instability of curved variable angle tow composite panel under axial compression, Thin-Walled Structures, 138, pp. 302-312.

32. Wu, Z., Raju, G., Weaver, P.M., 2018, Optimization of postbuckling behaviour of variable thickness composite panels with variable angle tows: Towards "Buckle-Free" design concept, International Journal of Solids and Structures, 132, pp. 66-79.

33. Viglietti, A., Zappino, E., Carrera, E., 2019, Free vibration analysis of variable angle-tow composite wing structures, Aerospace Science and Technology, 92, pp. 114-125.

34. Vescovini, R., Dozio, L., 2016, A variable-kinematic model for variable stiffness plates: Vibration and buckling analysis, Composite Structures, 142, pp. 15-26.

35. Minera, M.P.S., Carrera, E., Petrolo, M., Weaver, P.M., Pirrera, A., 2018, Three-dimensional stress analysis for beam-like structures using Serendipity Lagrange shape functions, International Journal of Solids and Structures, 141-142, pp. 279-296.

36. Patni, M., Minera, S., Groh, R., Weaver, P., Pirrera, A., 2019, Efficient 3D stress capture of variable stiffness and sandwich beam structures, AIAA Scitech 2019 Forum.

37. Patni, M., Minera, S., Groh, R.M.J., Pirrera, A., Weaver, P.M., 2019, On the accuracy of localised 3D stress fields in tow-steered laminated composite structures, Composite Structures, 225, 111034

38. Carrera, E., Pagani, A., Valvano, S., 2017, Shell elements with through-the-thickness variable kinematics for the analysis of laminated composite and sandwich structures, Composites Part B: Engineering, 111, pp. 294-314

39. Alesadi, A., Galehdari, M., Shojaee, S., 2017, Free vibration and buckling analysis of cross-ply laminated composite plates using Carrera's unified formulation based on Isogeometric approach, Comput Struct, 183(C), pp. 38-47. 
40. Carrera, E., Valvano, S., 2017, Analysis of laminated composite structures with embedded piezoelectric sheets by variable kinematic shell elements, Journal of Intelligent Material Systems and Structures, 28(20), pp. 2959-287.

41. Carrera, E., Fiordilino, G.A., Nagaraj, M., Pagani, A., Montemurro, M., 2019, A global/local approach based on CUF for the accurate and efficient analysis of metallic and composite structures, Engineering Structures, 188, pp. 188-201.

42. Carrera, E., Pagani, A., 2015, Accurate response of wing structures to free-vibration, load factors, and nonstructural masses, AIAA Journal, 54(1), pp. 227-241.

43. Yan, Y., Pagani, A., Carrera, E., 2017, Exact solutions for free vibration analysis of laminated, box and sandwich beams by refined layer-wise theory, Composite Structures, 175, pp. 28-45.

44. Vidal, P., Gallimard, L., Polit, O., 2012, Composite beam finite element based on the Proper Generalized Decomposition, Computers \& Structures, 102-103, pp. 76-86.

45. Khdeir, A.A., Redd, J.N., 1994, Buckling of cross-ply laminated beams with arbitrary boundary conditions, Composite Structures, 37(1), pp. 1-3.

46. Carrera, E., Garcia de Miguel, A., Pagani, A., Petrolo, M., 2016, Analysis of curved composite structures through refined $1 D$ finite elements with aerospace applications, ASME 2016 International Mechanical Engineering Congress and Exposition: American Society of Mechanical Engineers, pp. V001T03A8-VT03A8.

47. Carrera, E., 1998, Evaluation of layerwise mixed theories for laminated plates analysis, AIAA Journal. 36(5), pp. 830-839.

48. Carrera, E., Zappino, E., 2015, Carrera unified formulation for free-vibration analysis of aircraft structures, AIAA Journal, 54(1), pp. 280-292.

49. Carrera, E., Pagani, A., Petrolo M., 2015, Refined 1D finite elements for the analysis of secondary, primary, and complete civil engineering structures, Journal of Structural Engineering, 141(4), 04014123.

50. Ibrahim, S.M., Carrera, E., Petrolo, M., Zappino, E., 2012, Buckling of composite thin walled beams by refined theory, Composite Structures, 94(2), pp. 563-570.

51. Carrera, E., Pagani, A., Banerjee, J.R., 2016, Linearized buckling analysis of isotropic and composite beamcolumns by Carrera Unified Formulation and dynamic stiffness method, Mechanics of Advanced Materials and Structures, 23(9), pp. 1092-1103.

52. Wu, Z., Weaver, P.M., Raju, G., Chul Kim, B., 2012, Buckling analysis and optimisation of variable angle tow composite plates, Thin-Walled Structures, 60, pp. 163-172.

53. Chen, X., Wu, Z., Nie, G., Weaver, P., 2018, Buckling analysis of variable angle tow composite plates with a through-the-width or an embedded rectangular delamination, International Journal of Solids and Structures, 138, pp. 166-180.

54. Carrera, E., Cinefra, M., Petrolo, M., Zappino, P., 2014, Finite Element Analysis of Structures through Unified Formulation, John Wiley \& Sons.

55. Carrera, E., Pagani, A., Cabral, P.H., Prado, A., Silva, G., 2017, Component-wise models for the accurate dynamic and buckling analysis of composite wing structures, ASME 2016 International Mechanical Engineering Congress and Exposition, Phoenix, Arizona, USA.

56. Carrera, E., Petrolo, M., 2012, Refined beam elements with only displacement variables and plate/shell capabilities, Meccanica, 47(3), pp. 537-556.

57. Reddy, J.N., 1993, An evaluation of equivalent-single-layer and layerwise theories of composite laminates, Composite Structures, 25(1), pp. 21-35.

58. Viglietti, A., Zappino, E., Carrera, E., 2019, Analysis of variable angle tow composites structures using variable kinematic models, Composites Part B: Engineering, 171, pp. 272-283. 